NASA/TM-2005-213821

Effect of Free Jet on Refraction and Noise

\author{
Abbas Khavaran \\ QSS Group, Inc., Cleveland, Ohio
}

Nicholas J. Georgiadis, James E. Bridges, and Vance F. Dippold III Glenn Research Center, Cleveland, Ohio 
Since its founding, NASA has been dedicated to the advancement of aeronautics and space science. The NASA Scientific and Technical Information (STI) Program Office plays a key part in helping NASA maintain this important role.

The NASA STI Program Office is operated by Langley Research Center, the Lead Center for NASA's scientific and technical information. The NASA STI Program Office provides access to the NASA STI Database, the largest collection of aeronautical and space science STI in the world. The Program Office is also NASA's institutional mechanism for disseminating the results of its research and development activities. These results are published by NASA in the NASA STI Report Series, which includes the following report types:

- $\quad$ TECHNICAL PUBLICATION. Reports of completed research or a major significant phase of research that present the results of NASA programs and include extensive data or theoretical analysis. Includes compilations of significant scientific and technical data and information deemed to be of continuing reference value. NASA's counterpart of peerreviewed formal professional papers but has less stringent limitations on manuscript length and extent of graphic presentations.

- TECHNICAL MEMORANDUM. Scientific and technical findings that are preliminary or of specialized interest, e.g., quick release reports, working papers, and bibliographies that contain minimal annotation. Does not contain extensive analysis.

- CONTRACTOR REPORT. Scientific and technical findings by NASA-sponsored contractors and grantees.
- CONFERENCE PUBLICATION. Collected papers from scientific and technical conferences, symposia, seminars, or other meetings sponsored or cosponsored by NASA.

- SPECIAL PUBLICATION. Scientific, technical, or historical information from NASA programs, projects, and missions, often concerned with subjects having substantial public interest.

- TECHNICAL TRANSLATION. Englishlanguage translations of foreign scientific and technical material pertinent to NASA's mission.

Specialized services that complement the STI Program Office's diverse offerings include creating custom thesauri, building customized databases, organizing and publishing research results ... even providing videos.

For more information about the NASA STI Program Office, see the following:

- Access the NASA STI Program Home Page at http://www.sti.nasa.gov

- E-mail your question via the Internet to help@sti.nasa.gov

- Fax your question to the NASA Access Help Desk at 301-621-0134

- Telephone the NASA Access Help Desk at 301-621-0390

- Write to:

NASA Access Help Desk

NASA Center for AeroSpace Information 7121 Standard Drive

Hanover, MD 21076 
NASA/TM-2005-213821

AIAA-2005-2941

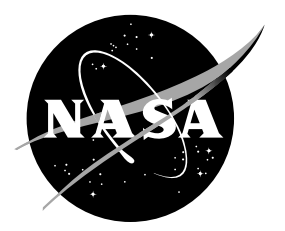

\section{Effect of Free Jet on Refraction and Noise}

Abbas Khavaran

QSS Group, Inc., Cleveland, Ohio

Nicholas J. Georgiadis, James E. Bridges, and Vance F. Dippold III

Glenn Research Center, Cleveland, Ohio

Prepared for the

11th Aeroacoustics Conference

cosponsored by the American Institute of Aeronautics and Astronautics and the Confederation of European Aerospace Societies

Monterey, California, May 23-25, 2005

National Aeronautics and

Space Administration

Glenn Research Center 
Available from

NASA Center for Aerospace Information 7121 Standard Drive

Hanover, MD 21076
National Technical Information Service 5285 Port Royal Road Springfield, VA 22100

Available electronically at http://gltrs.grc.nasa.gov 


\title{
Effect of Free Jet on Refraction and Noise
}

\author{
Abbas Khavaran \\ QSS Group, Inc. \\ Cleveland, Ohio 44135 \\ Nicholas J. Georgiadis, James E. Bridges, and Vance F. Dippold III \\ National Aeronautics and Space Administration \\ Glenn Research Center \\ Cleveland, Ohio 44135
}

\begin{abstract}
This article investigates the role of a free jet on the sound radiated from a jet. In particular, the role of an infinite wind tunnel, which simulates the forward flight condition, is compared to that of a finite wind tunnel. The second configuration is usually used in experiments, where the microphones are located in a static ambient medium far outside the free jet. To study the effect of the free jet on noise, both propagation and source strength need to be addressed. In this work, the exact Green's function in a locally parallel flow is derived for a simulated flight case. Numerical examples are presented that show a reduction in the magnitude of the Green's function in the aft arc and an increase in the forward arc for the simulated flight condition. The effect of finite wind tunnel on refraction is sensitive to the source location and is most pronounced in the aft arc. A Reynolds-averaged Navier-Stokes solution (RANS) yields the required mean flow and turbulence scales that are used in the jet mixing noise spectrum calculations. In addition to the sound/flow interaction, the separate effect of source strength and elongation of the noise-generating region of the jet in a forward flight is studied. Comparisons are made with experiments for the static and finite tunnel cases. Finally, the standard free-jet shear corrections that convert the finite wind tunnel measurements to an ideal wind tunnel arrangement are evaluated.
\end{abstract}

\section{Introduction}

Forward flight is generally believed to reduce the jet noise emission due to the reduced shear. Experimentally, simulation of the flight and its effect on jet noise is carried out in either an open wind tunnel (OWT) or an ideal wind tunnel (IWT). In the first configuration, the primary jet is surrounded by a co-flow (free-jet) with Mach number $M_{\infty}$ that simulates the flight Mach number, while the microphones are positioned outside the free stream in the stationary atmosphere. In the second arrangement, also referred to as an infinite wind tunnel, the microphones are positioned inside the co-flow to avoid the ambiguities associated with the refraction correction. In order for the microphones to be in the far field of the acoustic sources, the tunnel flow needs to extend far enough in the span-wise direction.

Obviously, in either case, the measurements are carried out with fixed microphones.

In practice, the OWT measurements are corrected for the secondary shear layer refraction, using semi-empirical corrections equations. The usual practice (ref. 1) is to replace the free jet shear layer with a vortex-sheet and to consider the source along the jet center line-and use a three-step calibration procedure for angle, distance, and sound amplitude. This procedure takes advantage of the high frequency geometric acoustics arguments, i.e., conservation of acoustic energy along a ray tube, and converts the noise measured outside the free jet to the levels that would be measured in an IWT. These simplifications, among other factors, ignore the difference between the on-axis and offaxis source location (ref. 2) as well as the additional noise generated by the free-jet shear layer.

Having completed the IWT simulation, the actual flight conditions may be addressed correctly only when the observer is set in motion relative to the stationary nozzle, at a velocity that equals the IWT velocity. The frequency and the spectral density measured by such a moving microphone are related to those observed by the stationary microphone. This final step recreates the relative motion of an airplane with respect to a stationary observer on the ground.

Most semi-empirical predictions methods (refs. 3 and 4) exploit the usual Lighthill's $V^{8}$ scaling law and write the overall sound pressure level in flight as $V_{r e l}^{m} V^{n}$, where $V_{\text {rel }}$ is the jet exit velocity relative to the ambient. The flight exponent factor $m$ is allowed to change from 5 to 7.2 depending on the angle, and factor $n$ is close to 3.0. 
Michalke and Michel (refs. 5 and 6) used a convected form of Lighthill's equation and proposed scaling laws that calculate the reduction level of the sideline sound intensity from static to flight. Tanna and Morris (ref. 7) examined the noise reduction in the forward flight from unheated jets, and suggested that a relative flight exponent factor of 5.5 shows reasonable agreement with the $90^{\circ}$ measurements. Tam et al. (ref. 8) studied the influence of forward flight on the sources of fine-scale turbulence mixing noise in an OWT simulation. They calculated the mean flow using specified velocity and temperature profiles at the jet exit that simulated an OWT case, and demonstrated a reduction in the jet turbulent kinetic energy and its radiated noise along the sideline.

The reduced shear due to the forward flight velocity affects not only the source intensity and its spectral distribution (ref. 9), but also the sound propagation. The purpose of the present work is to present a prediction method that accounts for source modification as well as refraction of sound due to flight and to provide a measure of comparison between the IWT and OWT simulations relative to the static case. The Green's function (GF) for a static ambient medium (refs. 10 and 11) is now extended to the IWT condition via the adjoint method-and is calculated exactly in an axisymmetric jet. The subsequent spectral predictions show that noise reduction in flight is not uniform throughout the spectrum at all angles. There is less high frequency reduction at small aft angles. Examination of the source spectral density demonstrates that flight tends to stretch the noise-producing region of the jet plume and reduce its peak intensity level. These results and in particular the mean flow effect on propagation from static to OWT and IWT cases will be explored and compared with the usual shear layer refraction correction.

The paper is organized in the following order. The Green's function formulation in an IWT simulation is described in section 2 and is utilized in jet noise calculations described in section 3. Sample numerical examples using a closed-form mean velocity profile are shown in section 4. Details of the GF in numerically computed jets are addressed is section 5, and the GF is mapped for the entire jet at selective observer angles and frequencies in static as well as in IWT and OWT simulations. The influence of forward flight on both the source spectral density and the stretching of the noise producing regions of a jet is studied in section 6. Section 7 examines the far-field noise in various simulations and compares those results with the OWT data as well as with the refraction-corrected data using a guideline commonly practiced in industry. A transformation from the IWT simulation to the actual flight condition is described in section 8 . Section 9 provides the final summary and conclusions.

\section{Formulation}

The adjoint Lilley equation governing a harmonic point source with frequency $\omega$ is

$$
L_{a}\left[\mathbf{G}_{a}\left(\vec{x}, \vec{x}^{o}, \omega\right) e^{-i \omega t}\right]=c_{\infty}^{2} e^{-i \omega t} \delta\left(\vec{x}-\vec{x}^{o}\right)
$$

where $L_{a}$ denotes the adjoint operator in a locally parallel flow (ref. 11), and $\mathbf{G}_{a}$ is the adjoint Green's function which relates to the direct Green's function $\mathbf{G}$ by switching the source and observer locations

$$
\mathbf{G}\left(\vec{x}^{o}, \vec{x}^{s}, \omega\right)=\mathbf{G}_{a}\left(\vec{x}^{s}, \vec{x}^{o}, \omega\right) .
$$

Consider the case when the main jet is surrounded by an infinite free-stream. Outside the jet, we should have

$$
U=U_{\infty}, \quad \rho=\rho_{\infty}, \quad p=p_{\infty}, \quad \text { as } r \rightarrow \infty .
$$

In the ambient medium, equation (1) becomes

$$
\left\{-\left(i \omega+U_{\infty} \frac{\partial}{\partial x_{1}}\right)^{3}+c_{\infty}^{2}\left(i \omega+U_{\infty} \frac{\partial}{\partial x_{1}}\right) \nabla^{2}\right\} \mathbf{G}_{a}=c_{\infty}^{2} \delta\left(\vec{x}-\vec{x}^{o}\right) .
$$

The solution to equation (4) that satisfies the outgoing wave conditions is

$$
\mathbf{G}_{a}=-\frac{1}{4 \pi i \widetilde{\omega}\left|\vec{x}-\vec{x}^{o}\right|} \exp \left\{i \frac{\widetilde{\omega}}{c_{\infty}}\left|\vec{x}-\vec{x}^{o}\right|\right\}, \quad \widetilde{\omega} \equiv \frac{\omega}{1+M_{\infty} \cos \theta},
$$


Where $M_{\infty} \equiv U_{\infty} / c_{\infty}$ is the ambient Mach number and the polar angle $\theta$ is measured from down stream jet axis, $\cos \theta=\left(x_{1}^{o}-x_{1}\right) /\left|\vec{x}^{o}-\vec{x}\right|$. Wave number $\widetilde{k}$ is now defined as

$$
\widetilde{k} \equiv \widetilde{\omega} / c_{\infty}
$$

Upon introducing the spherical coordinates $(R, \theta, \varphi)$, with $R$ measured from the jet exit centerline and the azimuthal angle $\varphi$ measured in a span-wise plane, we write equation (5) as

$$
\mathbf{G}_{a}=\frac{i}{4 \pi c_{\infty} \widetilde{k} R} \exp \left\{-i \widetilde{k}\left(x_{1} \cos \theta+x_{2} \sin \theta-R\right)\right\}, \quad r \rightarrow \infty
$$

The above plane wave expression may be written as a superposition of cylindrical functions

$$
\mathbf{G}_{a}=\frac{e^{-i \widetilde{k}\left(x_{1} \cos \theta-R\right)}}{4 \pi c_{\infty} \widetilde{k} R} \sum_{m=0}^{\infty}(-i)^{m} \varepsilon_{m} J_{m}(\widetilde{k} r \sin \theta) \cos m\left(\varphi-\varphi^{o}\right), \quad r \rightarrow \infty
$$

In the free stream $r \geq R_{0}, U=U_{\infty}$, and the scattered part of the Green's function is written in terms of wave number $\widetilde{k}$ as

$$
\mathbf{G}_{a}^{(s)}=\frac{e^{-i \widetilde{k}\left(x_{1} \cos \theta-R\right)}}{4 \pi c_{\infty} \widetilde{k} R} \sum_{m=0}^{\infty} h_{m}(r, \widetilde{k}, \theta) \cos m\left(\varphi-\varphi^{o}\right), \quad r \geq R_{o}
$$

The adjoint GF in the far-field is a sum of the incident and scattered waves

$$
\mathbf{G}_{a}=\underset{r \rightarrow \infty}{\mathbf{G}_{a}}+\mathbf{G}_{a}^{(s)}, \quad r \geq R_{o}
$$

Substituting equation (10) into equation (4) and upon noticing that equation (8) already satisfies equation (4), then equation (9) should satisfy the homogeneous form of equation (4)

$$
\nabla^{2} \mathbf{G}_{a}^{(s)}+\widetilde{k}^{2} \mathbf{G}_{a}^{(s)}=0
$$

Equation (11) has a solution as the mth-order Hankel function $H_{m}^{(1)}(\widetilde{k} r \sin \theta)$

$$
\mathbf{G}_{a}^{(s)}=\frac{e^{-i \widetilde{k}\left(x_{1} \cos \theta-R\right)}}{4 \pi c_{\infty} \widetilde{k} R} \sum_{m=0}^{\infty} A_{m} H_{m}^{(1)}(\widetilde{k} r \sin \theta) \cos m\left(\varphi-\varphi^{o}\right), \quad r \geq R_{o}
$$

Using equation (8) and equation (12) into equations (10), the outer solution is now matched with the inner solution

$$
\mathbf{G}_{a}\left(\vec{x}^{s}, \vec{x}^{o}, \omega\right)=\mathbf{G}\left(\vec{x}^{o}, \vec{x}^{s}, \omega\right)=\frac{e^{-i \widetilde{k}\left(x_{1} \cos \theta-R\right)}}{4 \pi c_{\infty} \widetilde{k} R} \sum_{m=0}^{\infty} f_{m}(r, \widetilde{k}, \theta) \cos m\left(\varphi-\varphi^{o}\right), \quad r \leq R_{o}
$$

at the jet boundary $r=R_{o}$, i.e., the two solutions and their radial derivatives are set equal.

After substituting the inner solution equation (13) into the homogeneous form of equation (1), the function $f_{m}$ is found to satisfy the compressible Rayleigh equation 


$$
\begin{aligned}
& f_{m}^{\prime \prime}+\left[\frac{1}{r}-\frac{\rho^{\prime}}{\rho}-4 \cos \theta \frac{\widetilde{M}^{\prime}}{(1-\widetilde{M} \cos \theta)}\right] f_{m}^{\prime}+ \\
& {\left[\frac{\widetilde{\omega}^{2}}{c^{2}}(1-\tilde{M} \cos \theta)^{2}-\frac{m^{2}}{r^{2}}-\frac{\widetilde{\omega}^{2}}{c_{\infty}^{2}} \cos ^{2} \theta+\frac{3 \cos \theta}{(1-\tilde{M} \cos \theta)}\left(\frac{\rho^{\prime}}{\rho} \tilde{M}^{\prime}-\frac{1}{r} \tilde{M}^{\prime}-\tilde{M}^{\prime \prime}\right)\right] f_{m}=0,}
\end{aligned}
$$

where

$$
\tilde{M}=M-M_{\infty}, \quad \text { and } \quad M=\frac{U(r)}{c_{\infty}}
$$

In equation (14), prime denotes a radial derivative. Notice that for a given observer frequency $\omega$, the above adjoint equation is solved in a frame of reference moving with $U_{\infty}$ and $\widetilde{\omega}$ as defined in equation (5) is the frequency observed in this reference frame. As $r \rightarrow \infty, \widetilde{M}$ as well as $\widetilde{M}^{\prime}$ and $\rho^{\prime}$ approach zero and equation (14) reduces to Helmholtz equation (11), thus stratifying the matching conditions at the jet boundary.

The numerical solution to (14) starts with $f_{m}=a_{m} r^{m}$ as $r \rightarrow 0$, and continues to the jet boundary $r=R_{o}$ where the matching conditions are applied to determine $A_{m}$ and $a_{m}$

$$
\begin{gathered}
a_{m}=(-i)^{m} \varepsilon_{m} \frac{\tilde{k} \sin \theta\left[J_{m}(\chi) H_{m}^{(1)}(\chi)-J_{m}^{\prime}(\chi) H_{m}^{(1)}(\chi)\right]}{\widetilde{k} \sin \theta f_{m}\left(R_{o}\right) H_{m}^{(1)}(\chi)-d f_{m}\left(R_{o}\right) / d r H_{m}^{(1)}(\chi)} \\
\chi=\widetilde{k} R_{o} \sin \theta, \quad \varepsilon_{m}=\left(2-\delta_{m 0}\right), \quad m=0,1,2, \ldots
\end{gathered}
$$

In equation (16), prime as appearing on the Bessel and Hankel functions points to a derivative with respect to the argument.

\section{Application to Jet Noise}

The above Green's function is now extended to a moving type singularity of interest in jet noise. The governing equation is Lilley's third-order wave equation. This equation is linearized about a unidirectional transversely sheared mean flow (ref. 12)

$$
\begin{gathered}
p_{o}=\text { constant }, \quad U_{i}=\delta_{i 1} U\left(x_{2}, x_{3}\right), \quad T_{o}=T_{o}\left(x_{2,} x_{3}\right) \\
L \pi^{\prime}=\frac{D}{D t} \frac{\partial \zeta_{i}}{\partial x_{i}}-2 \frac{\partial U}{\partial x_{i}} \frac{\partial \zeta_{i}}{\partial x_{1}} \\
\zeta_{i} \equiv \frac{\partial}{\partial x_{j}}\left(1+\pi^{\prime}\right) u_{i} u_{j}+(\gamma-1) \mathrm{h}^{\prime} \frac{\partial \pi^{\prime}}{\partial x_{i}}
\end{gathered}
$$

$L$ is linearized Lilley operator, $\zeta_{i}$ denotes the equivalent source component in a Lilley-type acoustic analogy, and the convective derivative is $D / D t \equiv \partial / \partial t+U \partial / \partial x_{1} . \vec{x} \equiv\left(x_{1}, x_{2}, x_{3}\right)$ are the Cartesian coordinates and $x_{1}$ is in the stream-wise direction, $t$ is time, $\pi^{\prime} \equiv\left(p / p_{o}\right)^{1 / \gamma}-1, p$ is pressure and $p_{o}$ is the mean pressure, (i.e., $\left.p \equiv p_{o}+p^{\prime}\right), T_{o}$ is the mean temperature, $u_{i}$ is the fluctuating velocity component $u_{i}=v_{i}-\delta_{i 1} U, \mathrm{~h}$ ' denotes enthalpy fluctuation $\mathrm{h}^{\prime}=(\gamma-1)\left(c^{2}\right)^{\prime}$, which is related to fluctuations in sound speed $\left(c^{2}\right)^{\prime}=\gamma \mathfrak{R}\left(T-T_{o}\right)$. Since pressure fluctuations $p^{\prime}$ are small relative to mean pressure $p_{o}$, the dependent variable is approximated as $\pi^{\prime} \cong p^{\prime} /\left(\gamma p_{o}\right)$. 
In isothermal jets, the source term associated with enthalpy fluctuations is neglected, and equation (18a) is approximated as

$$
\zeta_{i} \cong \frac{\partial u_{i} u_{j}}{\partial x_{j}}
$$

The two source terms on the right hand side of equation (17) are usually referred to as self- and shear noise terms.

Consider a convecting harmonic point source with a source frequency $\omega^{\mathrm{s}}$ and convection velocity $\hat{i} U_{c}$. The GF associated with the first source term in equation (17) is

$$
L\left(G e^{-i \omega t}\right)=\frac{D}{D t}\left\{c_{\infty}^{2} e^{-i \omega^{s} t} \delta\left(x_{1}-U_{c} t\right) \delta\left(\vec{x}_{t}-\vec{x}_{t}^{s}\right)\right\}
$$

Subscript $t$ denotes a transverse location. The above GF is derived from the stationary simple-source GF (eq. 13), and the convolution integral. Following the steps described in (ref. 10) it is shown that

$$
G\left(\vec{x}, \vec{x}^{s}, \omega\right)=\frac{-i}{4 \pi R} \frac{\left(1-\widetilde{M}^{s} \cos \theta\right)}{\left(1-\widetilde{M}_{c} \cos \theta\right)} e^{i \widetilde{k} R} \sum_{m=0}^{\infty} f_{m}\left(r^{s}, \widetilde{k}, \theta\right) \cos m\left(\varphi-\varphi^{s}\right)
$$

Wave number $\widetilde{k}$ was defined in equation (6) and

$$
M^{s}=U\left(r^{s}\right) / c_{\infty}, \quad M_{c}=U_{c} / c_{\infty}, \quad \tilde{M}_{c}=M_{c}-M_{\infty} .
$$

In deriving equation (20), the requirement that the time harmonic factor $\exp (-i \omega t)$ should cancel out from both sides of the equation results in the following definition for the Doppler factor

$$
\omega=\frac{\omega^{s}\left(1+M_{\infty} \cos \theta\right)}{1-\widetilde{M}_{c} \cos \theta}
$$

Since $M_{c} \rightarrow 0$ as $\mathrm{r} \rightarrow \infty$, then $\omega \rightarrow \omega^{\mathrm{s}}$ in the infinite free stream.

In axisymmetric jets, the source intensity is constant along a ring in a span-wise plane at $\left(x_{1}^{s}, r^{s}\right)$. A ring source directivity factor is defined below that is used in conjunction with the source/GF volume integration

$$
D^{2}\left(\vec{x}, \vec{x}^{s}, \omega\right) \equiv \frac{(4 \pi R)^{2}}{2 \pi} \int_{-\pi}^{+\pi}\left|G\left(\vec{x}, \vec{x}^{s}, \omega\right)\right|^{2} d \varphi^{s}
$$

\section{Numerical Example}

To demonstrate the effect of the free-stream flow on the Green's function, consider a jet profile described as

$$
\begin{aligned}
& \frac{\rho(r)}{\rho_{\infty}}=1 \\
& \frac{U(r)}{c_{\infty}}=M_{\infty}+\left(M_{J}-M_{\infty}\right) \operatorname{sech}^{2}\left(2 r / D_{J}\right) .
\end{aligned}
$$


The above mean velocity profile is shown in figure 1 using a jet Mach number of $M_{J}=0.90$. Two profiles using the static $M_{\infty}=0.0$ and the ideal wind tunnel conditions $\mathrm{M}_{\infty}=0.18$ are examined.

A third profile is also shown that is obtained by subtracting

$$
\frac{U(r)}{c_{\infty}}=M_{\infty}\left\{1-\operatorname{sech}^{2}\left(2 r / D_{J}-4\right)\right\}, \quad r>2 D_{J}
$$

from equation (23a). This profile, seen as dash-dot, decays from a free-stream value of $M_{\infty}=0.18$ to 0.0 at $r>2 D_{J}$, thus simulating an open wind tunnel condition.

The directivity factor $D$ as defined in equation (22) was calculated numerically for the three mean flow profiles shown in figure 1. Figures 2 to 5 show the effect of the mean flow on a stationary ring source $\left(U_{\mathrm{c}}=0.0\right)$, at a Strouhal number $S t \equiv \omega D_{J} /\left(2 \pi U_{J}\right)$ of 0.50 . The static case $M_{\infty}=0.0$, as well as the IWT and OWT simulation is shown at a flight Mach number of $M_{\infty}=0.18$. Figure 2 shows that in the vicinity of the peak directivity angle, and prior to the zone of relative silence, there is stronger refraction and beaming of sound arising from a two-steps layer (i.e., OWT) compared to a single shear layer (i.e., IWT). As the source moves away from the centerline, the OWT shear layers could surpass even the static case in its sound beaming in the direction of the peak directivity angle (figs. 3 and 4). In the forward arc, for the most part, there is little difference between these two profiles - and both simulations appear to amplify the sound relative to the static case at very large forward angles.

In general, the effect of the infinite wind tunnel, compared to the static conditions, may be surmised from figures 2 and 3, as a reduction of noise in the aft arc and an increase in the utmost forward arc. Thus, the infinite free stream plays opposing roles in the forward and aft arcs.

It is noted that when calculating the actual jet noise spectrum, source strength needs to be convolved with an appropriate GF. Turbulence intensity, and hence the source strength, are affected by a reduction in the mean shear due to the presence of the free jet. This should naturally lower the jet noise level at $90^{\circ}$ even though the isothermal GF appears unaffected as discussed above.

\section{Mapping of the Green's Function}

To further illustrate the mean flow effect on the radiated sound in a jet, it is of interest to study the GF in more detail as a function of the source location and jet profile. For this purpose, we consider a numerically computed jet at $M_{J}=0.98, T_{r}=1.0$ (i.e., $U_{J} / \mathrm{c}_{\infty}=0.90$ ), and select secondary flow streams that would simulate both the IWT and OWT conditions. Table 1 shows the secondary Mach, or $M_{\infty}$ for simulations that follow.

TABLE 1.-MACH 0.98 UNHEATED JET

\begin{tabular}{|l|l|}
\hline IWT Mach no. & OWT Mach no. \\
\hline 0.00 & \\
\hline 0.10 & 0.10 \\
\hline 0.20 & 0.20 \\
\hline 0.28 & 0.28 \\
\hline
\end{tabular}

Mean flow predictions (RANS) were generated using the WIND flow solver (refs. 13 and 14) available at the NASA Glenn Research Center. The inflow conditions are specified at five diameters upstream of the jet exit plane, and in terms of plenum total pressure and temperature. In order to establish a given Mach number for the outer flow, the static pressure and the desired free-stream Mach number are used to calculate the inflow total pressure. Similarly, the inflow total temperature is defined from the static temperature and the free-stream Mach. While in an IWT simulation, these two conditions are set as constant throughout inflow boundary, an OWT simulation requires a gradual reduction in the inflow total pressure and temperature to their respective static ambient values in an interval, say $5.5 D_{J}$ to $7 D_{J}$. This method is advantageous over an alternative that would specify inflow velocity and temperature profiles-as it closely simulates the actual test conditions, allows for the secondary entrainment, and lets the required mean velocity and temperature profiles in an OWT simulation to develop ahead of the nozzle exit. The presence of the ambient flow, in either simulation, elongates the length of the potential core and reduces the peak turbulent kinetic energy (see figs. 6 and 7). 
The RANS grid extends 40 diameters downstream of the nozzle exit plane, and 20 diameters in the span-wise direction. The mean axial velocity profiles (fig. 8) are shown for the static as well as the $M_{\infty}=0.20$ (IWT and OWT) simulations. Similar illustrations are presented for the turbulent kinetic energy profiles (fig. 9). At a radial distance of $10 D_{J}$ (not shown in fig. 9), the turbulent kinetic energy level decays throughout the jet to $0.0,0.80$, and 2.5 percent for the static, IWT, and OWT simulations respectively. Between the IWT and OWT simulations the peak turbulence levels are very close, consequently the additional free-stream turbulence (larger scales) tend to produce relatively more low frequency noise in the OWT case as will be shown in section 7.

The ring directivity factor $D$ in equation (22) was calculated at selective inlet angles of $\left(60^{\circ}, 90^{\circ}, 120^{\circ}\right.$, and $150^{\circ}$ ) throughout the computational domain starting from the jet exit plane. Using a locally parallel flow model, the mean temperature $T(x, r)$ and axial velocity $U(x, r)$ were used in the equation (14). The number of modes required to achieve a converged solution in equation (20) would increase with frequency. Results are presented for a stationary source $\left(M_{c}=0.0\right)$ at three Strouhal numbers of $S t=(0.10,0.50,3.0)$, and using maximum mode numbers of $m=(7,10,20)$, respectively. Three simulations are shown: (1) static $M_{\infty}=0$; (2) IWT with $M_{\infty}=0.20$; and (3) OWT with $M_{\infty}=0.20$.

The Green's function $D$ as defined in equation (22) is mapped as a function of source location at $S t=0.10$ (fig. 10) at four angles in each simulation. Identical color legends are shown at equal angles in order to highlight the differences in the three simulations (seen side-by-side). The static GF could have an amplifying effect on the sound radiated to $150^{\circ}$ if volume sources are located near the centerline at 4 to 7 diameters from the jet exit. Fortunately there is very little turbulent kinetic energy present in this vicinity, which coincides with the jet potential core (see fig. 7). Between the IWT and OWT simulations, the latter demonstrates stronger low frequency directionality at $120^{\circ}$ and $150^{\circ}$ observer angles.

Figures 11 and 12 exhibit similar comparisons at $S t=0.50$ and 3.0, respectively. At shallow aft angles, the OWT flow achieves a more intense high frequency refraction compared to its IWT counterpart (see fig. 12). Subsequent spectrum predictions confirm this observation.

\section{Source Spectral Density}

Flight reduces the peak turbulent kinetic energy and stretches the noise-producing region of a jet. It also affects the time-and length-scales of a noise generating turbulent eddy. The far-field spectra from source terms of equation (17) have been studied under the static condition (ref. 10). Those results are readily extended to a simulated flight case (app. A) using the GF definition provided in equation (20). The far-field sound at each observer angle and frequency of interest is now calculated from a volume integration of equations (A1) and (A2) over the entire jet volume.

Sound spectral density, when calculated per unit axial slice at each stream-wise grid coordinate, provides valuable insight into the source strength and its spectral distribution as affected by flight. For simplicity, consider a $90^{\circ}$ far-field observer at $R / D_{j}=100$. The sound spectral density (eq. A1) was calculated in a simulated flight at an observer Strouhal number range of 0.016 to 18.0.

Figure 13 shows the source spectral distribution in the first 25 diameters of the jet, using free jet Mach numbers of $0.0,0.20$, and 0.28 in an IWT simulation. Contour legends extend $20 \mathrm{~dB}$ from the peak in each simulation. High intensity noise producing sources move downstream in excess of 3 diameters as $M_{\infty}$ in increased from 0.0 to 0.28 .

An OWT simulation works similarly to reduce source intensity and shifts its maximum location. For example, figure 14 shows that there is very little difference in source distribution between the IWT and OWT simulations as viewed by an observer at $90^{\circ}$. Any spectral difference between the two simulations is primarily linked to the Green's function.

\section{Far-field Sound}

Spectrum predictions are presented for Mach 0.98 unheated jets issuing from a $5.08 \mathrm{~cm}$ (2.0 in.) convergent nozzle on an arc at $100 D_{J}$. The IWT simulations using ambient conditions of table 1 are shown in figure 15 . In the mid-angle range, there are 2.5- to $3 \mathrm{~dB}$ uniform reductions in sound level across the spectrum from one simulation to the next. At shallow angles, however, these reductions appear to diminish at high frequency (HF) as the tunnel Mach number is increased. Measurements shown in figure 15 are acquired at the Small Hot Jet Acoustics Rig (SHJAR) at the NASA Glenn Research Center, and are relevant to the static condition only (ref. 15).

As pointed out earlier, flight simulation measurements are usually carried out in an OWT flow, and are subsequently processed for the secondary shear layer refraction using semi-empirical correction relations. Figure 16 shows a comparison between the IWT and OWT far-field noise predictions at $M_{\infty}=0.10$. Two sets of data are also shown; (a) the actual measurements in an OWT simulation (ref. 16); (b) the IWT data that are obtained from the 
former set after utilizing the usual refraction correction recipe (ref. 1). All data are converted to a narrow band and are presented as lossless.

The differences in spectral levels between the two simulations become increasingly visible at aft angles. Both data and prediction indicate that at low frequency the OWT flow is noisier compared to its corresponding IWT flow. There is less agreement in the HF range however. Predictions suggest less HF noise at shallow angles in an OWT flow (relative to an IWT flow) due to a stronger HF refraction. The correction procedure remains rather insensitive to this observation. Similar conclusions can be drawn at $M_{\infty}=0.20$ as seen in figure 17 .

\section{Influence of Flight}

A transformation to the actual flight conditions can be carried out if the microphone is set in motion at $M_{\infty}$ within the IWT simulation. Such a microphone measures a frequency $\omega^{\prime}$ that relates to $\omega$ as measured by a stationary microphone according to $\omega^{\prime}=\omega\left(1+M_{\infty} \cos \theta\right)^{-1}$. Since the over all power level measured in either frame remains the same, the sound spectral intensity should change as $\omega^{\prime} I^{\prime}\left(\omega^{\prime}\right)=\omega I(\omega)$. This results in a dynamic factor that relates the spectral densities according to

$$
\overline{p^{\prime 2}}\left(\omega^{\prime}\right)=\left(1+M_{\infty} \cos \theta\right) \overline{p^{2}}(\omega) \text {. }
$$

Here prime refers to a moving microphone within an IWT - that would also represent a stationary observer listening to a fly-by airplane. Note that the spectral density on the right-hand-side of equation (24) is not that of a static condition, rather it is due to a stationary jet engine in an infinite wind tunnel simulation. Measurement of the actual jet mixing noise in flight is further complicated due to the presence of other types of sources, such as boundary layer noise produced by the flow around the engine nacelle and the external surfaces, and possible interaction between different types of sources. This might explain the commonly observed differences between the flight simulation experiments and flyover tests. Most semi-empirical relations proposed in the literature relate the static engine noise (i.e., $M_{\infty}=0$ ) to the actual flight noise. These models suggest a wide range of flight dynamic factors (refs. 3, 5, 7, and 17) that account for the jet stretching effect (fig. 13) and the reduction in source strength due to flight in one form or another.

Figure 18 shows the influence of the dynamic factor as defined in equation (24) on the sound spectral level and its frequency using a flyover Mach number of $M_{\infty}=0.20$. A comparison is also made with results shown earlier for a fixed microphone in an IWT simulation.

\section{Summary}

In this work, the effect of forward flight on the high-speed jet noise was investigated within the framework of a Lilley-type acoustic analogy. The influence of flight on the source spectral intensity and sound propagation was addressed in a systematic order. Both ideal wind tunnel and open wind tunnel simulations were studied using carefully specified RANS solutions that emulated the actual test conditions. It was argued that an IWT simulation more closely resembles the flight conditions, and reduces the spectral level in flight almost uniformly at sideline angles. At shallow aft angle, however, the high frequency noise reduction diminishes gradually as the flight Mach number is increased.

Theoretical predictions demonstrate that the difference between the two simulations becomes increasingly visible at smaller aft angles. This is evidenced by an increase in the low frequency noise and a decrease in high frequency noise in an OWT simulation as compared to its IWT counterpart. The commonly practiced refraction correction procedure appears to remain insensitive to this predicted HF noise difference between the two simulations.

Flight, moreover, moves and stretches the noise producing regions of a jet in the direction of the jet flow. This could have an impact on the performance of noise silencer kits in the static versus flight conditions. Transformation from an IWT simulation (with static microphones) to the actual flight resulted is a flight dynamic factor that amplified the noise in the aft angles and additionally modified the observer frequency due to the flight Doppler factor.

\section{Appendix A. Far-field Spectral Density}

Expressions for the far-field noise due to the source terms of equation (17) were provided in reference 10 assuming an isotropic turbulence, and using exponential functions to model both spatial and temporal dependencies 
of a two-point space-time correlation. The GF for a simulated flight as given in equation (20) is used to extend the previous static results to a simulated flight case

$$
\begin{aligned}
\overline{p_{\text {self }}^{2}}(\vec{x}, \vec{y}, \omega) \cong & \frac{1}{(4 \pi R)^{2}} \frac{\left(1-\widetilde{M}^{s} \cos \theta\right)^{6}}{\left(1-\widetilde{M}_{c} \cos \theta\right)^{2}}\left(\frac{\rho^{s}}{\rho_{\infty}}\right)^{2}\left(\rho_{\infty}^{2} I_{1111}\right) \widetilde{k}^{4} \sum_{m}\left|f_{m}\left(r^{s}, \widetilde{k}, \theta\right)\right|^{2}, \\
\overline{p_{\text {shear }}^{2}}(\vec{x}, \vec{y}, \omega) \cong & \frac{1}{(4 \pi R)^{2}} \frac{\left(\frac{2 d U / d r}{\widetilde{\omega}}\right)^{2}}{\left(1-\widetilde{M}_{c} \cos \theta\right)^{2}}\left(\frac{7}{2} \cos ^{2} \theta\right)\left(\cos ^{2} \theta+\frac{\left(1-\widetilde{M}^{s} \cos \theta\right)^{2}}{c^{2} / c_{\infty}^{2}}\right) \\
& \times\left(\rho_{\infty}^{2} I_{1111}\right) \widetilde{k}^{4} \sum_{m}\left|f_{m}\left(r^{s}, \widetilde{k}, \theta\right)\right|^{2} .
\end{aligned}
$$

The $4^{\text {th }}$ order axial correlation coefficient at source point $\vec{y}$ is

$$
I_{1111}\left(\vec{y}, \omega^{s}\right)=A_{m} \kappa^{7 / 2} \frac{\tau_{o}^{4}}{1+\left(\omega^{s} \tau_{o} / 2\right)^{2}} N(\tilde{k} \ell) .
$$

$\omega^{\mathrm{s}}$ is the source frequency which is related to the observer frequency according to equation (21), and $\ell \equiv c_{\ell} \kappa^{3 / 2} / \varepsilon, \tau_{o} \equiv c_{\tau} \kappa / \varepsilon$, where $\kappa$ and $\varepsilon$ are the turbulent kinetic energy is its dissipation rate. Parameters $\left(c_{\ell}, c_{\tau}, A_{m}\right)$ denote three calibration constants, and the source convection velocity is defined as $U_{c}=0.50 U(x, r)+0.25 U_{j}$.

Factor $N(\tilde{k} \ell)$ in (A3) represents a non-compactness factor that is determined from the spatial function of the correlation. Its argument $\widetilde{k} \ell=\left(c_{\ell} / c_{\tau}\right)\left(\widetilde{\omega} \tau_{o}\right)\left(\kappa^{0.5} / c_{\infty}\right)$, as discussed in (ref. 10), becomes self-similar when divided by the local acoustic Mach number $U\left(r^{\mathrm{s}}\right) / \mathrm{c}_{\infty}$. This modified argument is used in noise predictions. In the presence of a free jet with velocity $U_{\text {free }}$, (i.e., IWT or OWT simulations), $U\left(r^{\mathrm{s}}\right)$ should be measured with respect to the free-stream velocity as $U\left(r^{\mathrm{s}}\right)-U_{\text {free }}$.

\section{References}

1. Ahuja, K.K., Tester, B.J., and Tanna, H.K., "The Free Jets as a Simulator of Forward Velocity Effects on Jet Noise,"NASA CR-3056, 1978.

2. Schlinker, R.H., and Amiet, R.K., "Shear Layer Refraction and Scattering of Sound," AIAA Paper 80-0973, June 1980.

3. Cocking B.J., and Bryce W.D., "Subsonic Jet Noise in Flight Based on Some Recent Wind-Tunnel Tests," AIAA Paper 75-462, March 1975.

4. Cocking, B.J., "A Prediction Method for the Effect of Flight on Subsonic Jet Noise," J. Sound and Vibrations, 53(3), 1977, pp. 435-453.

5. Michalke A., and Michel U., "Prediction of Jet Noise in Flight from Static Tests," J. Sound and Vibration, 67(3), 1979, pp. 341-367.

6. Michalke A., and Michel U., "Relation Between Static and In-Flight Directivities of Jet Noise," J. Sound and Vibration, 63(4), 1979, pp. 602-605.

7. Tanna, H.K., and Morris, P.J., "In-Flight Simulation Experiments on Turbulent Jet Mixing Noise," J. Sound and Vibration, 53(3), 1977, pp. 389-405.

8. Tam, C.K.W., Pastouchenko. N., and Auriault, L., "The Effect of Forward Flight on Jet Mixing Noise from Fine-Scale Turbulence,” AIAA Paper 2000-2061, June 2000.

9. Larson, R.S., McColgan, C.J., and Packman, A.B., "Jet Noise Source Modification Due to Forward Flight," AIAA Journal, (16), March 1978, pp. 225-232.

10. Khavaran, A., and Bridges, J., "Modeling of Turbulence Generated Noise in Jets," AIAA Paper 2004-2983, May 2004. 
11. Tam, C.K.W. and Auriault, L., "Mean Flow Refraction Effects on Sound Radiated from a Localized Source in Jets," J. Fluid Mechanics, (370), 1999, pp. 149-174.

12. Goldstein, M.E., “An Exact from of Lilley's Equation with a Velocity Quadrupole/Temperature Dipole Source Term," J. Fluid Mechanics, (443), 2001, pp. 232-236.

13. Nelson, C.C., and Power, G.D., CHSSI Project CFD-7: The NPARC Alliance Flow Simulation System, AIAA Paper 2001-0594, January 2001.

14. Engblom, W.A., Georgiadis, N.J., and Khavaran, A., "Investigation of Variable-Diffusion Turbulence Model Correction for Round Jets," AIAA Paper 2005-3085, May 2005.

15. Bridges, J., and Warnet, M.P., "Measurements of the Acoustic Sound Source in Hot Jets," AIAA Paper 20033130, 2003.

16. Plumblee, H.E., "Effect of Forward Velocity on Turbulent Jet Mixing Noise," NASA CR-2702, July 1976.

17. Ffowcs Williams, J.E., "Jet Noise from Moving Aircraft," AGARD Conference Proceedings, no. 42, (8.1-8.7), 1969.

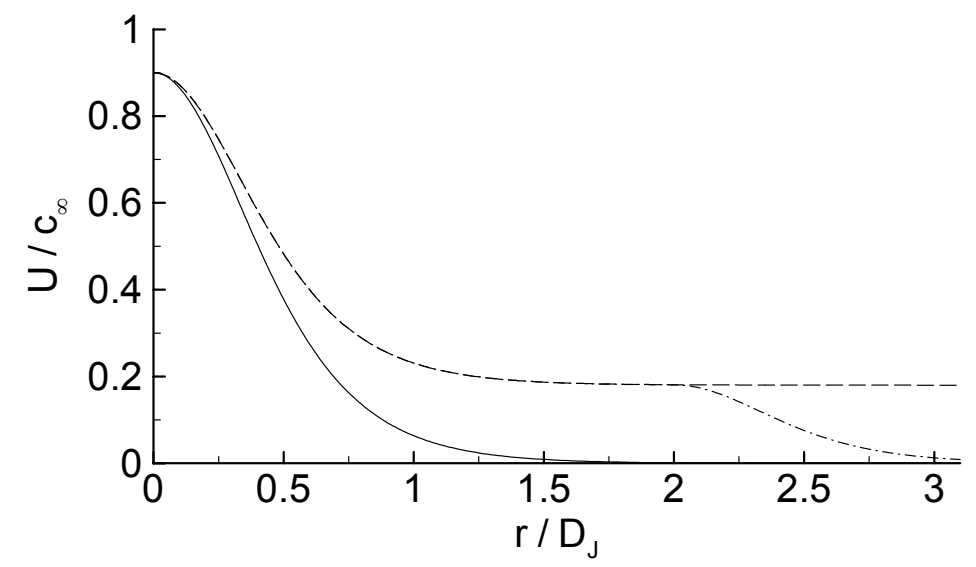

Figure 1.- Mean velocity profile with $M_{\infty}=0.0$ (solid line);

$\mathrm{M}_{\infty}=0.18$ ideal wind tunnel (dashed line); open wind tunnel (dash-dot).

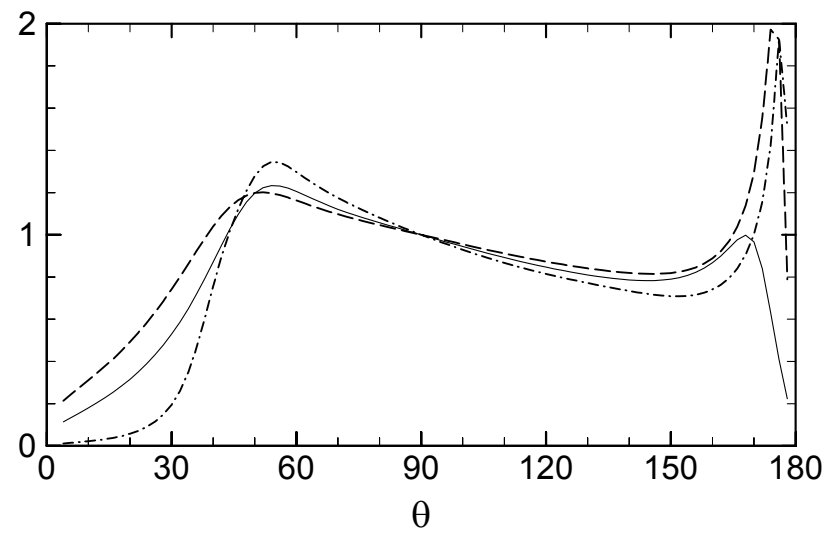

Figure 2.-Effect of the free jet on refraction. Green's function $D\left(\vec{x}, \vec{x}^{s}, \omega\right)$ at observer Strouhal number of $S t=0.50$ in an isothermal $M_{J}=0.90$ jet.

Source at $r^{\mathrm{s}} / D_{J}=0.0$ with: $M_{\infty}=0.0$, (solid line); $M_{\infty}=0.18$ IWT, (dashed line); OWT (dash-dot).

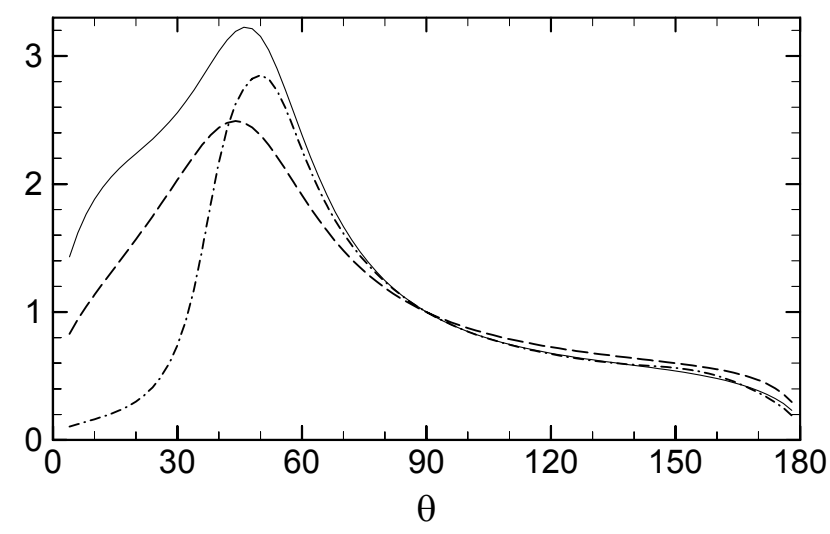

Figure 3.-As figure 2 but at $r^{\mathrm{s}} / D_{J}=0.50$. 


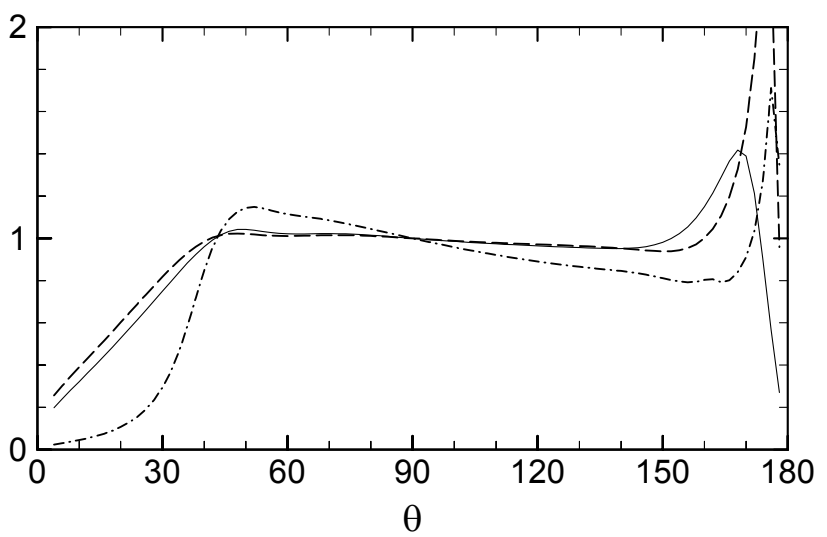

Figure 4.-As figure 2 but at $r^{\mathrm{s}} / D_{J}=1.0$.

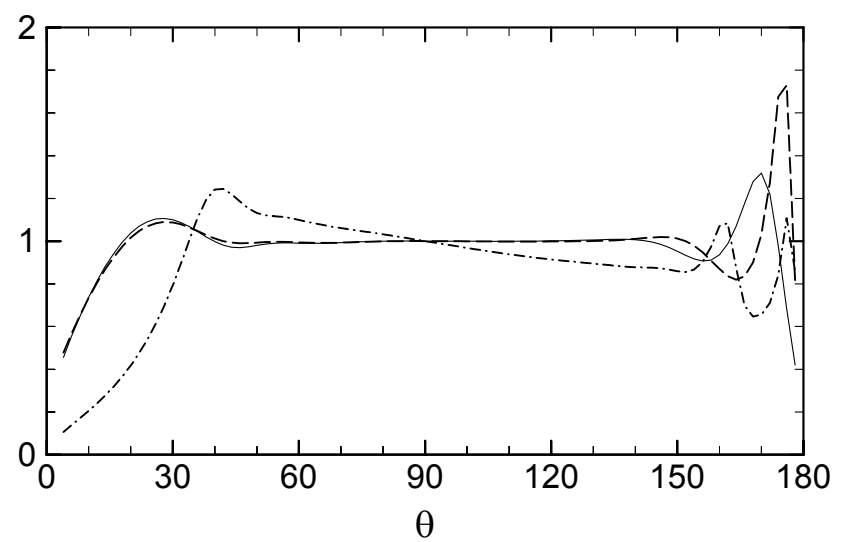

Figure 5.-As figure 2 but at $r^{\mathrm{s}} / D_{J}=2.0$.

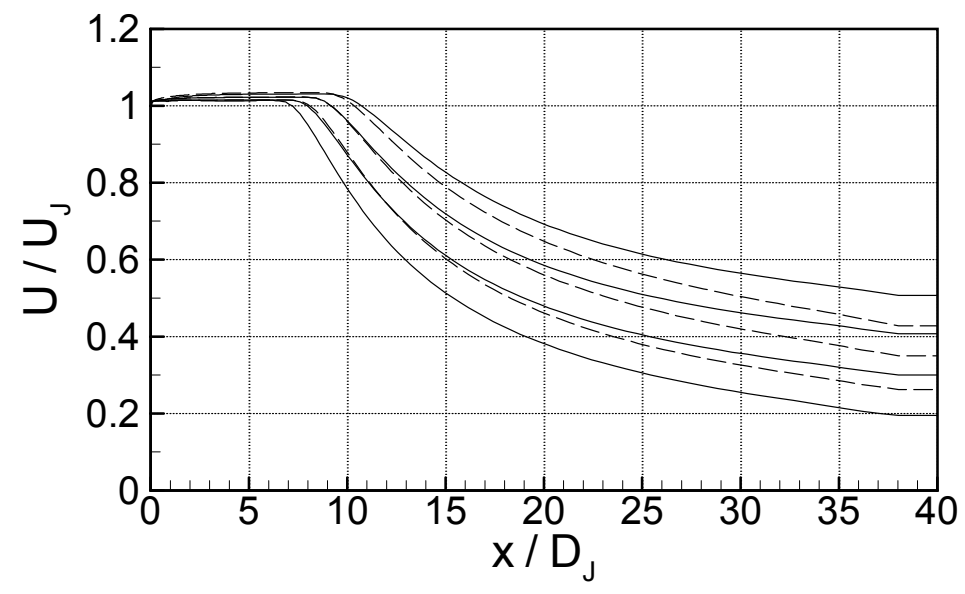

Figure 6.-Centerline velocity decay in a simulated flight, Mach 0.98 unheated jet. Solid lines (IWT), from the top: $M_{\infty}=0.28$, $0.20,0.10,0.0$. Dashed lines (OWT), from the top: $M_{\infty}=0.28$, $0.20,0.10$

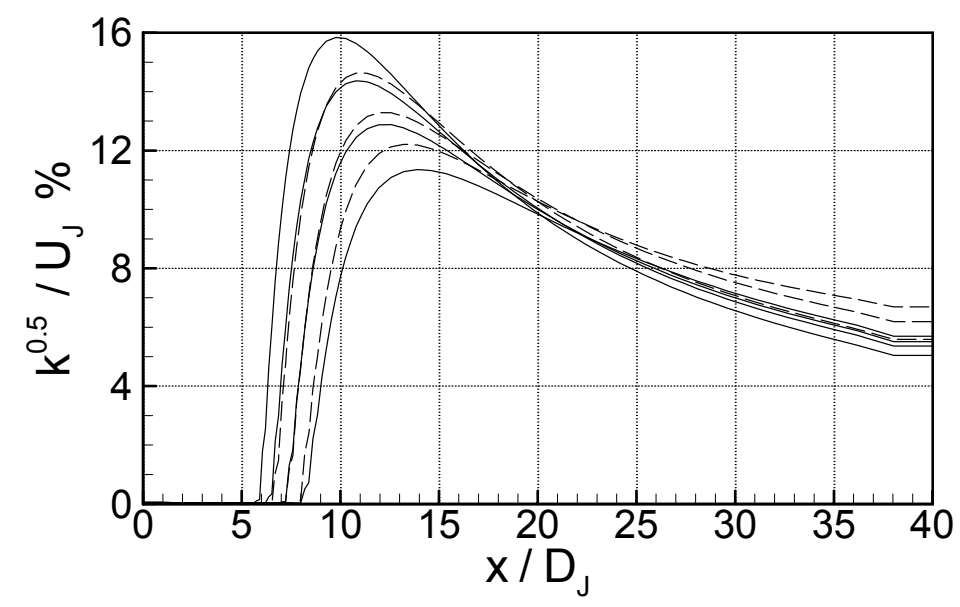

Figure 7.-Centerline turbulent kinetic energy in a simulated flight, Mach 0.98 unheated jet. Solid lines (IWT), from the 
bottom: $\mathrm{M}_{\infty}=0.28,0.20,0.10,0.0$. Dashed lines (OWT),

from the bottom: $\mathrm{M}_{\infty}=0.28,0.20,0.10$.
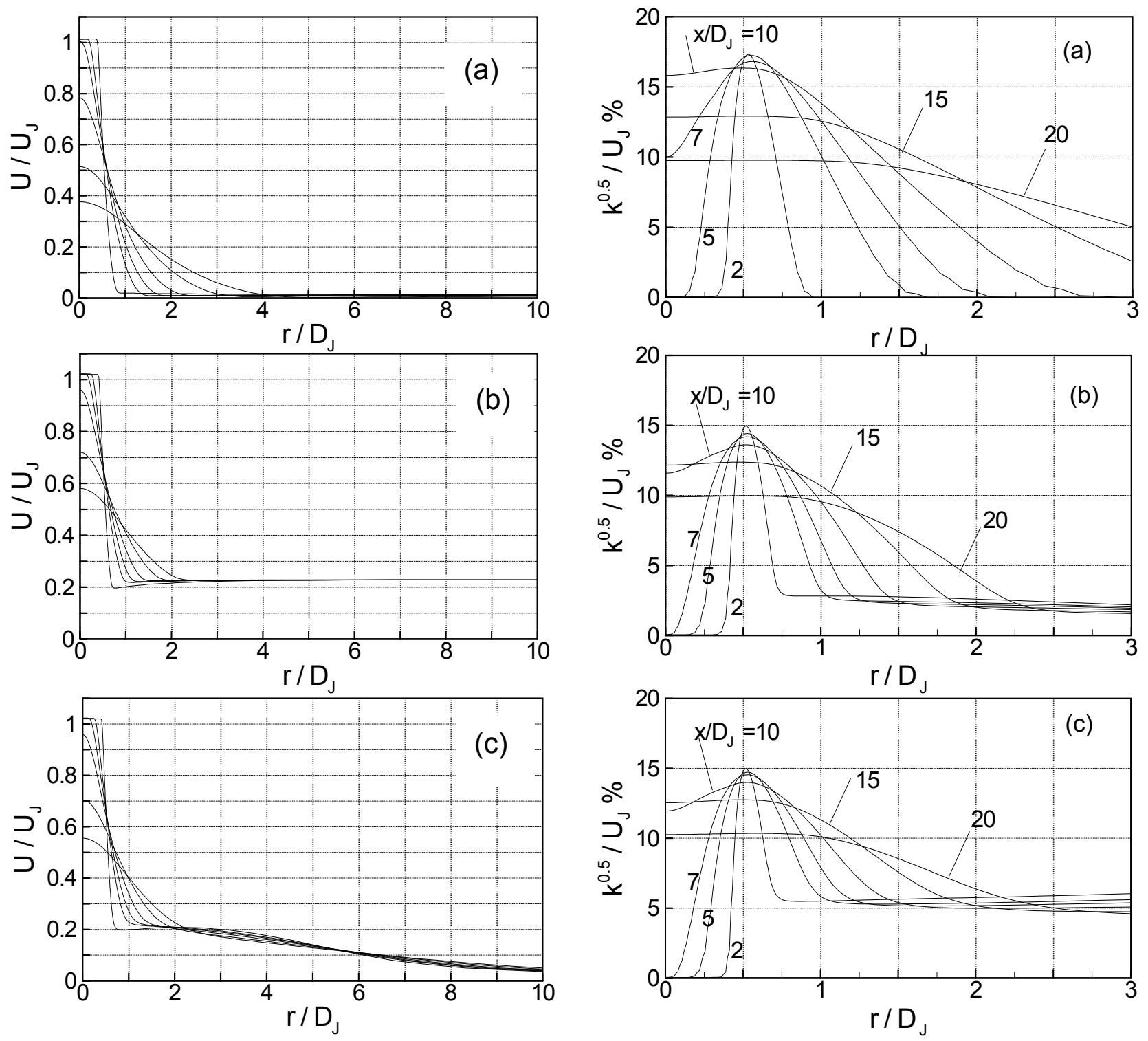

Figure 8.-Mean velocity profiles in a simulated flight, Mach 0.98 unheated jet. (a) $M_{\infty}=0.0$; (b) $M_{\infty}=0.20$ (IWT); (c) $M_{\infty}=0.20$ (OWT); at axial locations - starting from the top: $x / D_{J}=2,5,7,10,15,20$.

Figure 9.-Turbulent kinetic energy profiles in a simulated flight, Mach 0.98 unheated jet.
(a) $M_{\infty}=0.0$; (b) $M_{\infty}=0.20$ (IWT);
(c) $M_{\infty}=0.20(\mathrm{OWT})$. 

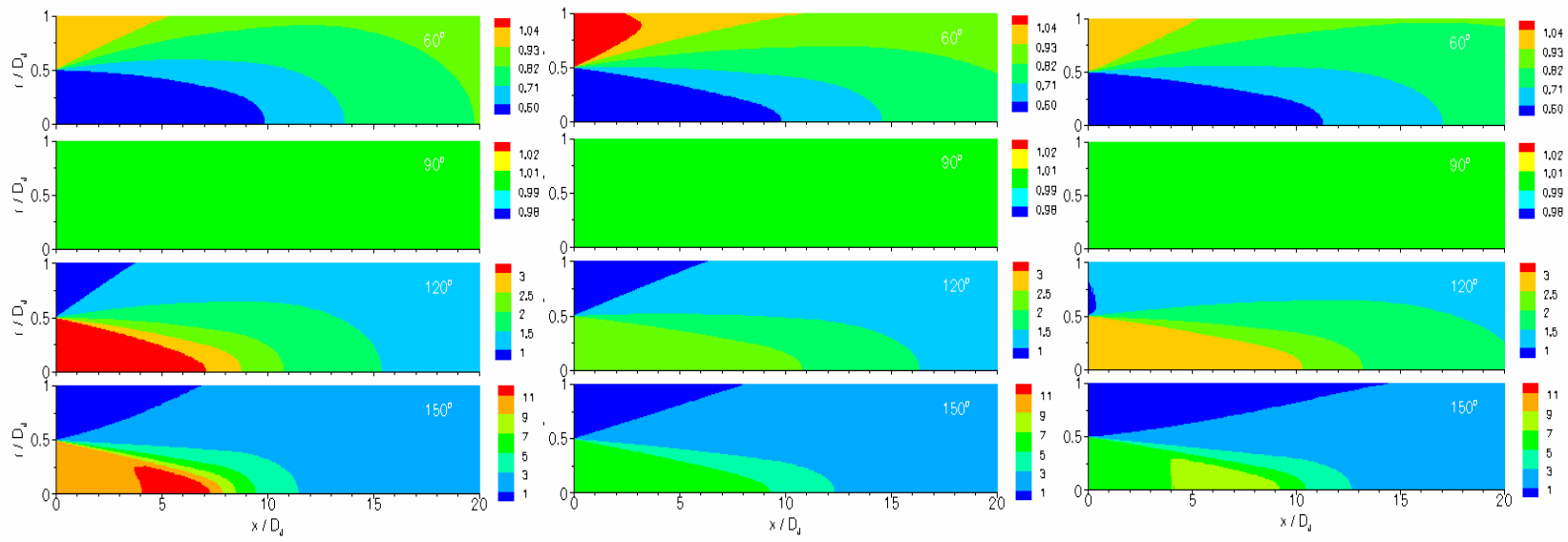

Figure 10. - Green's function mapped for a stationary monopole-type ring source in a Mach 0.98 unheated jet at $S t=0.10$. Inlet angles: from top $60^{\circ}, 90^{\circ}, 120^{\circ}$ and $150^{\circ}$. Free jet simulations: from left $\mathrm{M}_{\infty}=0.0 ; \mathrm{M}_{\infty}=0.20$ IWT; and $\mathrm{M}_{\infty}=0.20 \mathrm{OWT}$.
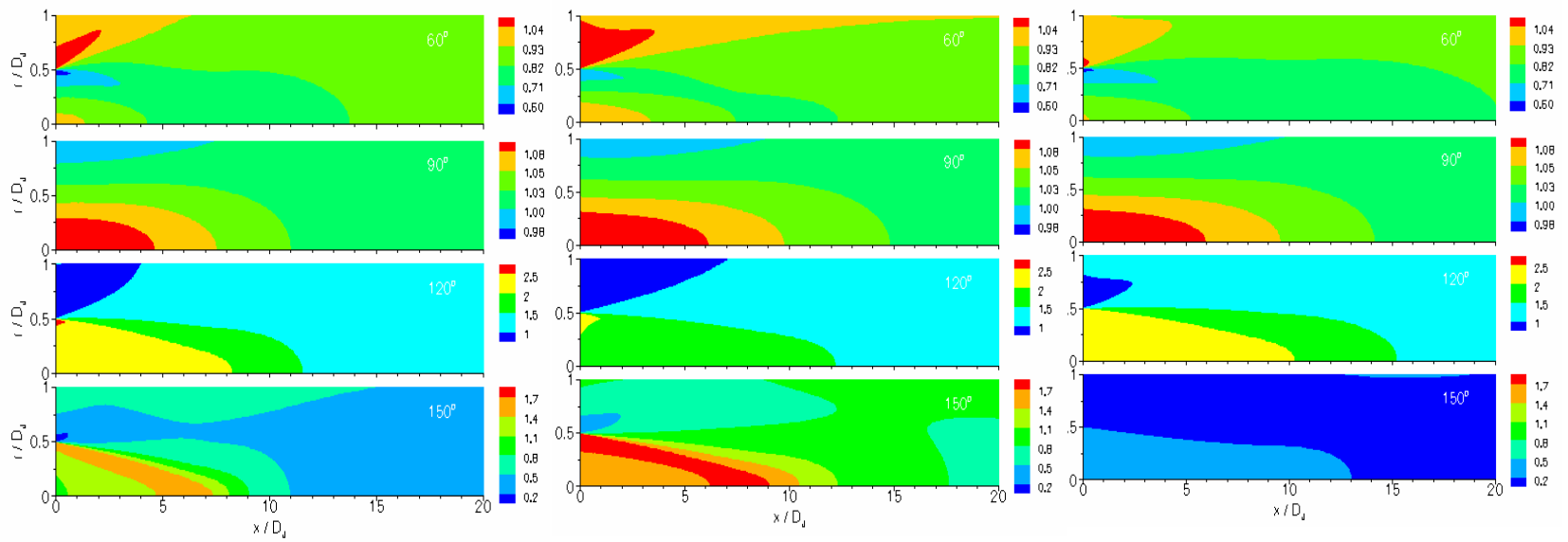

Figure 11. - As figure 10 but at $S t=0.50$.
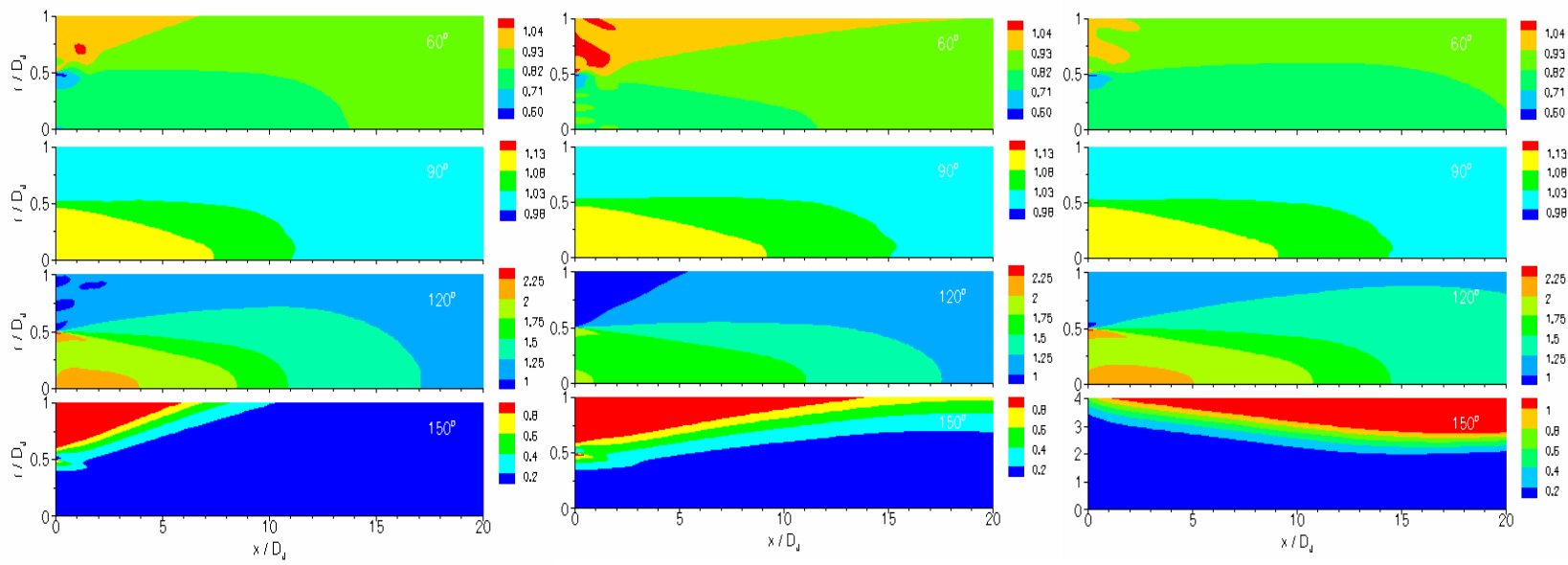

Figure 12.-As figure 10 but at $S t=3.0$. 

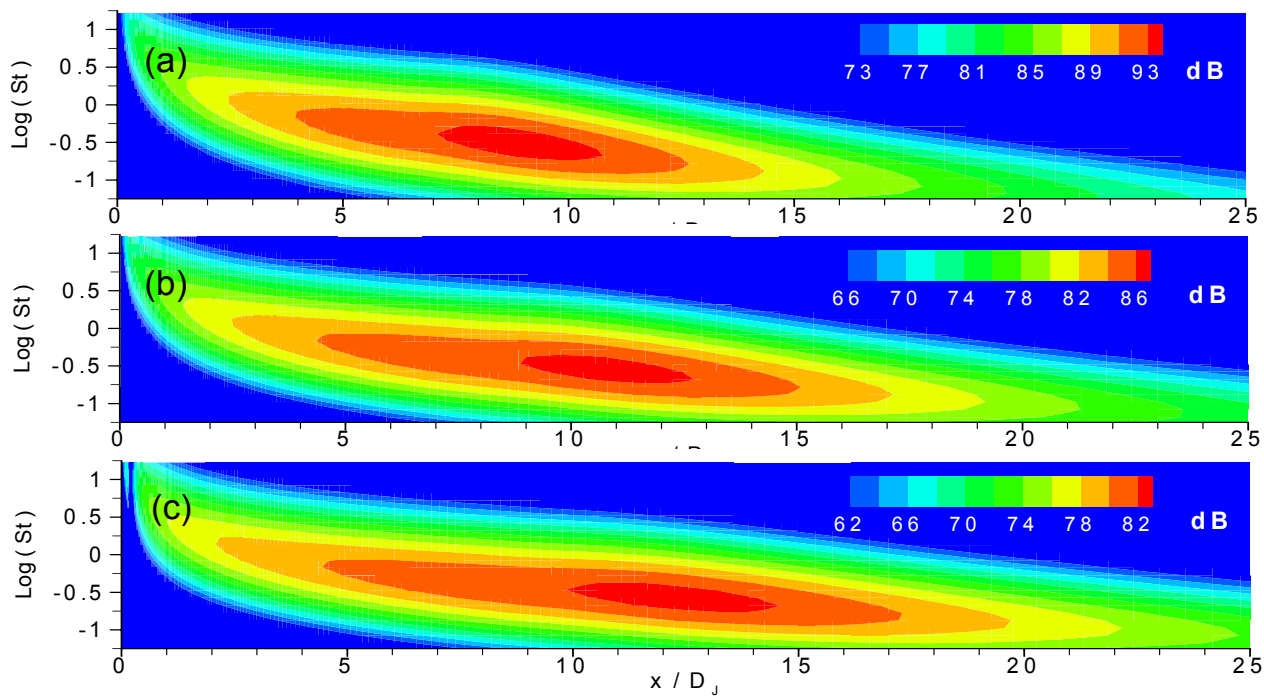

Figure 13.- Source spectral density per unit axial slice in a Mach 0.98 unheated jet at $90^{\circ}$, and at $R / D_{J}=100.0$. (a) $M_{\infty}=0.0$; (b) IWT, $M_{\infty}=0.20$; (c) IWT, $M_{\infty}=0.28$.

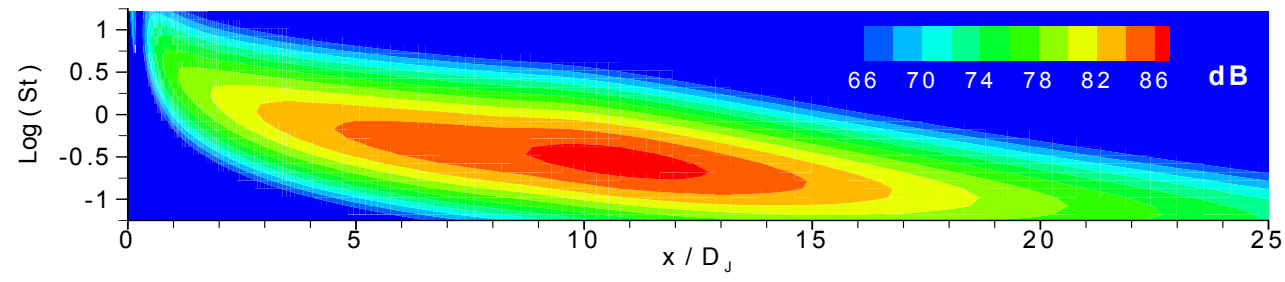

Figure 14.-As figure 13 , but in a $\mathrm{M}_{\infty}=0.20$ OWT simulation 

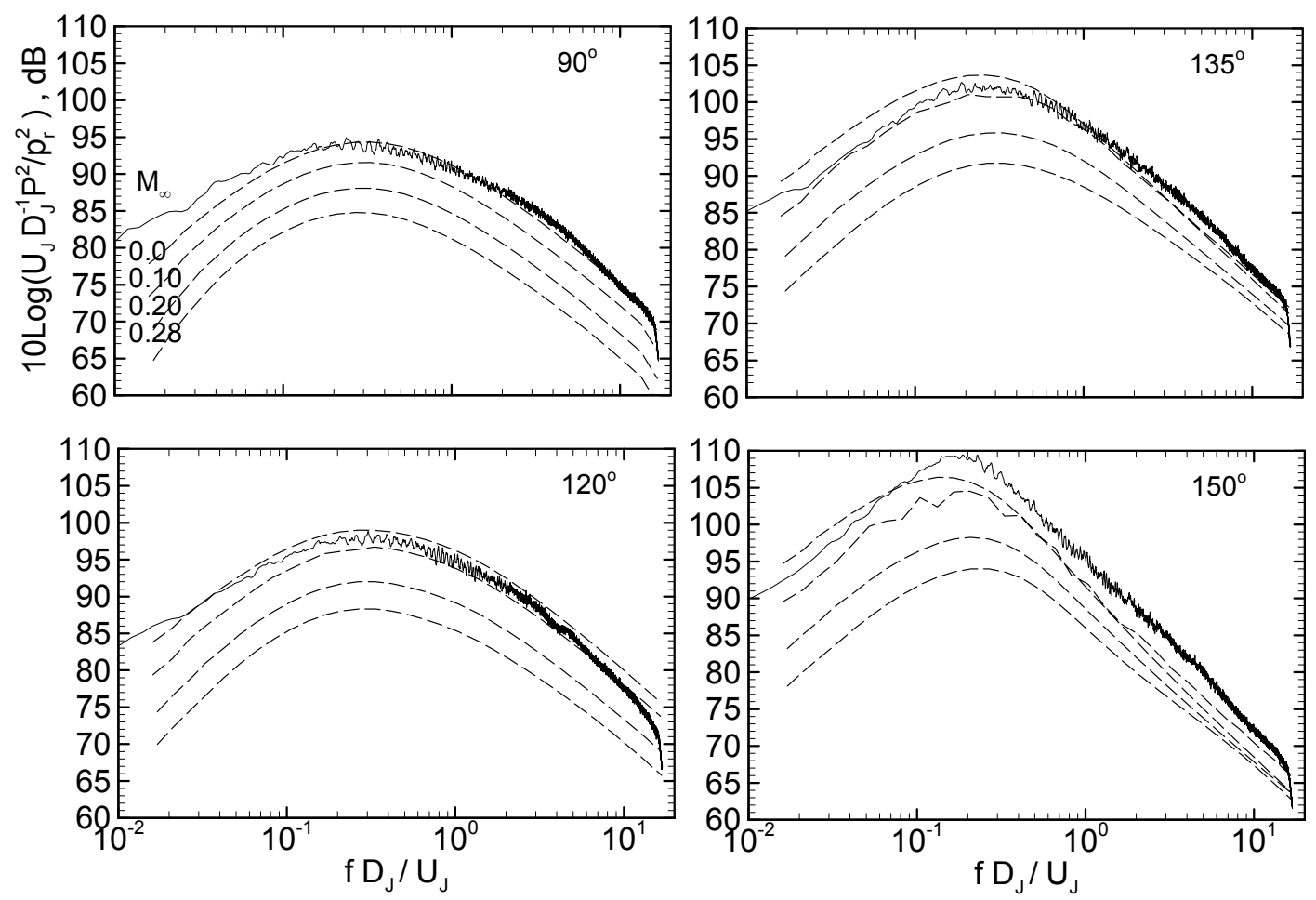

Figure 15.- Spectra in a Mach 0.98 unheated jet at indicated inlet angles and at $R / D_{J}=100$. Ideal Wind Tunnel simulation at $M_{\infty}=0.0,0.10,0.20,0.28$. Dashed line (prediction); solid line (static data-ref. 15).
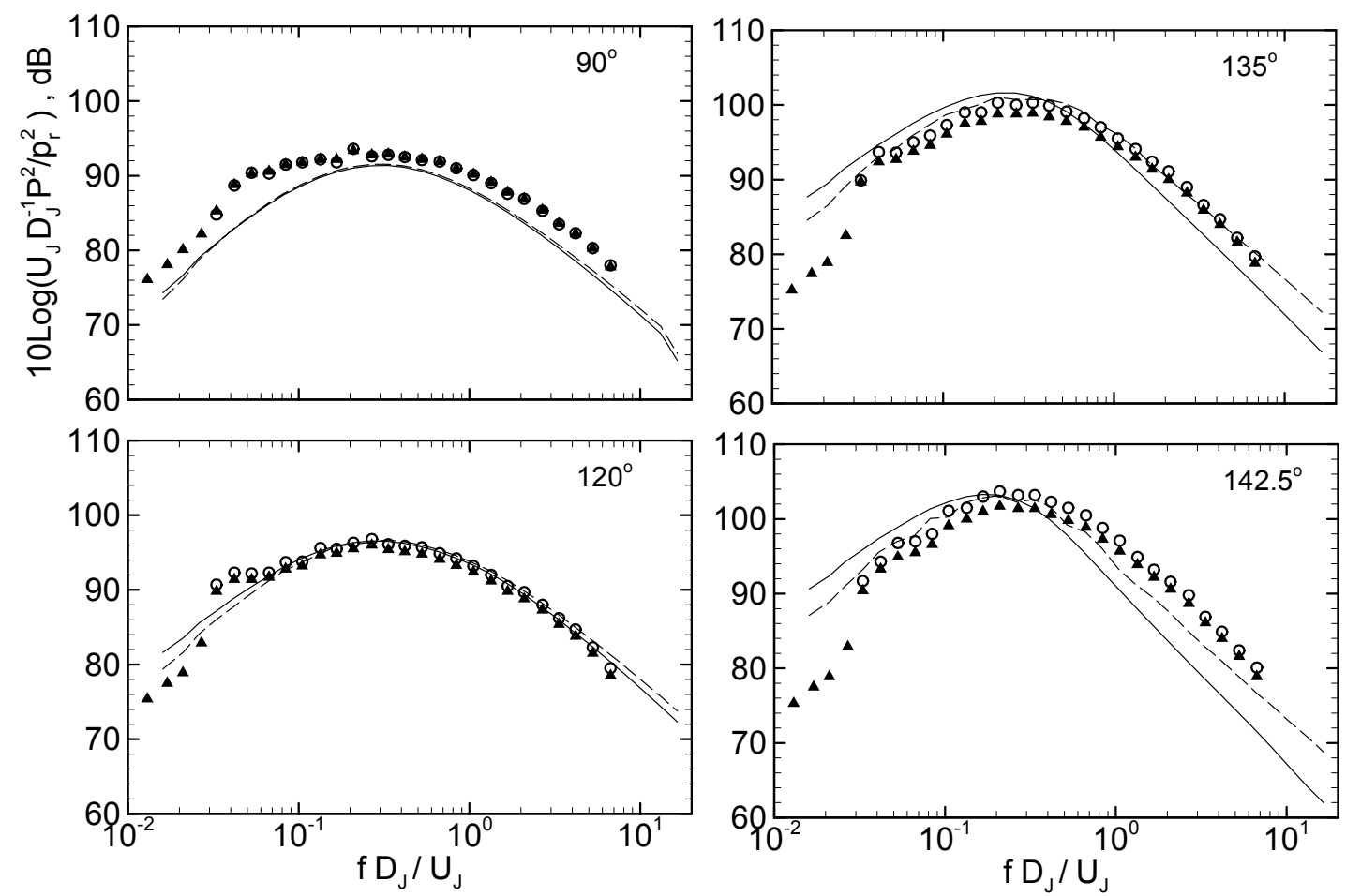

Figure 16.- Spectra in a Mach 0.98 unheated jet at $M_{\infty}=0.10$ and at indicated inlet angles. Predictions:

OWT (solid line); IWT (dashed line). Data: OWT (ref. 16), (open symbol); IWT correction

(filled symbol). 

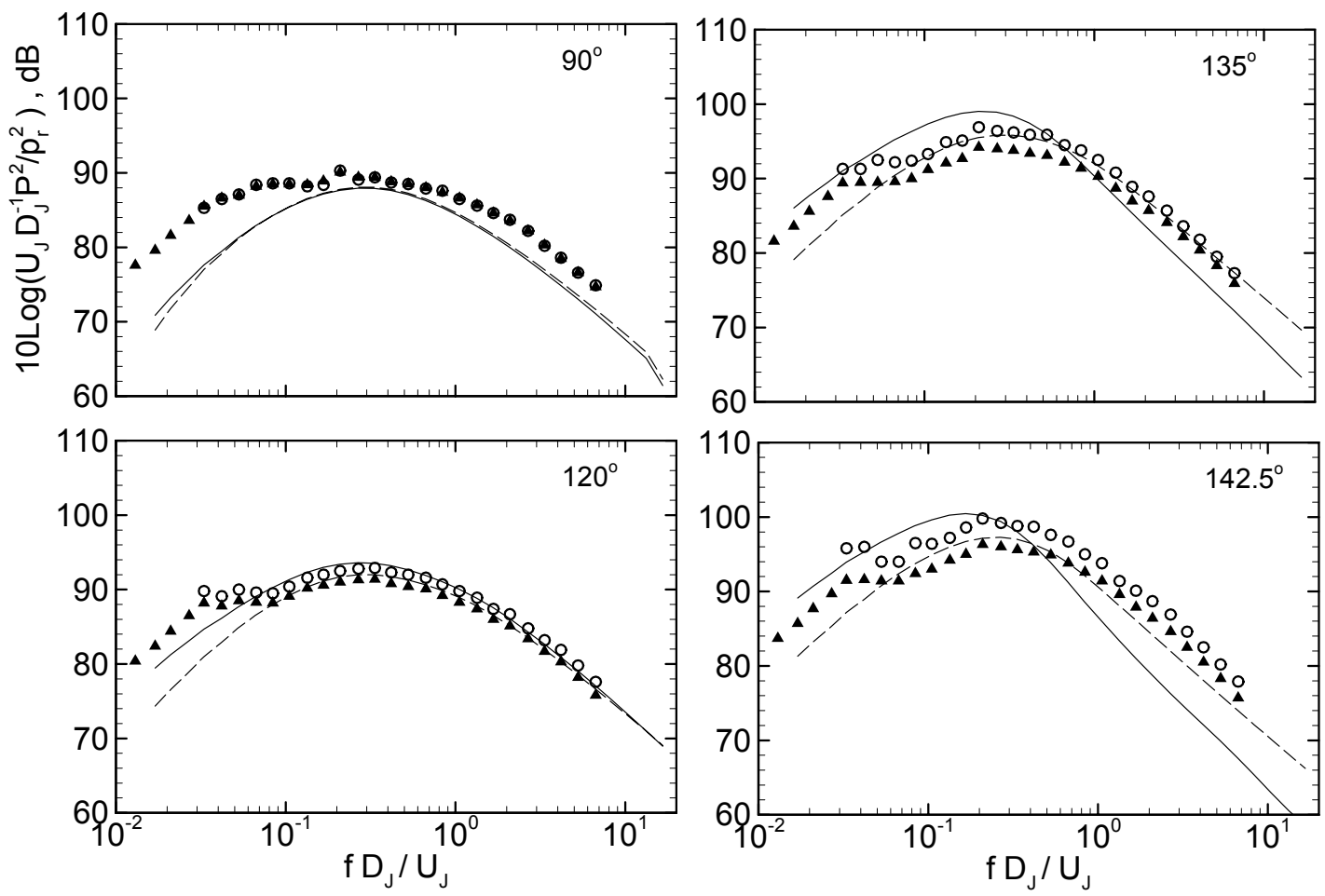

Figure 17. - As figure 16 but at $M_{\infty}=0.20$.

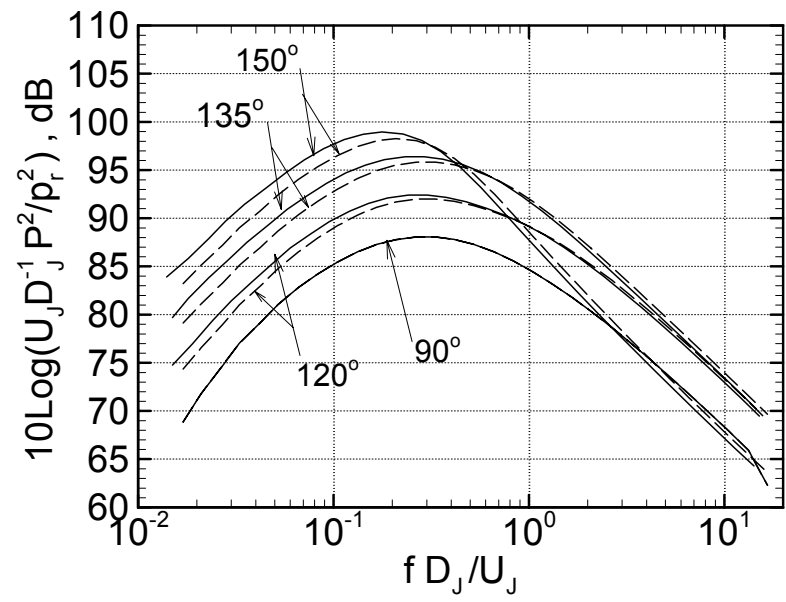

Figure 18.-Effect of airplane flyover on jet noise spectra in a Mach 0.98 unheated jet at $M_{\infty}=0.20$ and at indicated inlet angles. Predictions: IWT (dashed line); IWT with moving microphone (solid line). 

